\title{
Reduced fatalities related to rear seat shoulder belts
}

\author{
Leon S Robertson
}

\begin{abstract}
Objective-To determine the effect on fatality rates in crashes of installation of shoulder belts in automobile back seats. Methods-During 1988-96, fatalities to rear outboard seat occupants of passenger cars, classified by age of occupant and vehicle curb weight were matched to data on model year in which shoulder belts became standard equipment. The same data were obtained from the same years on back seat occupants in crashes from the Crashworthiness Data System. Weighted regression was performed on death rates per occupants in crashes by belt equipment, occupant age, and vehicle weight for all occupants and occupants who claimed to be restrained.

Results-The risk of death is significantly lower in vehicles equipped with shoulder belts, midsized to larger cars, and among children. Claimed child restraint use is higher in cars with shoulder belts and claimed use of shoulder belts is higher among adolescents and young adults but lower among those 35 and older. However, older occupants have lower death rates in shoulder belt equipped cars.

Conclusions-Shoulder belts substantially reduce risk of death relative to lap belts at prevalent use rates in each age group. Belt effectiveness when used cannot be estimated precisely because of invalid claimed use, but the lowered rates among vehicles with shoulder belts indicates that effectiveness given prevalent use is far more efficacious than lap belts without shoulder belts.

(Injury Prevention 1999;5:62-64)
\end{abstract}

Keywords: seat belts; belt use; child restraints; vehicle restraint effectiveness

Although the effect of seat belts in reducing injury to vehicle occupants in crashes is well grounded in physics, and can be demonstrated in crash tests, epidemiological research has produced an astonishing variation in estimates of their effects in on-road crashes. Old studies of effectiveness of belts when used, produced estimates ranging from an adverse effect to $80 \%$ injury reduction.

Recently, a claim of $89 \%$ belt effectiveness in reducing fatalities was sent to the United States
Congress by the current Administrator of the National Highway Traffic Safety Administration. This claim was based on matched hospital and police records in the Crash Outcome Data Evaluation System (CODES) project. ${ }^{2}$ Studies comparing belt users and non-users within the same vehicle at the time of impact ${ }^{3}$ and the use of belts in traffic by model year and calendar year in relation to death rates $^{4}$ indicate $40 \%-45 \%$ effectiveness of lap/shoulder belts in fatality reduction.

While some of the variation in effectiveness estimates in recent studies may be due to different configurations of belts, such as slack introduced by "windowshade devices" in certain American models, ${ }^{5}$ and lack of use of lap belts when shoulder belts automatically encircle front occupants, there are also biases in the data systems that are used to estimate belt effectiveness. The severity of cases selected, and the misreporting of belt use in relation to severity, can substantially bias the effectiveness estimates. Small differences in claimed use by non-users among the less severely injured results in large overestimates of belt effectiveness when used. ${ }^{1}$ The introduction of seat belt use laws has undoubtedly increased post-collision claims of use to police officers by non-users, probably accounting for the inflated CODES estimates. Police assessments of injury severity are not well correlated with clinical severity coding ${ }^{6}$ other than fatalities, and inclusion of all police reported injuries, or "severe" plus deaths, ${ }^{7}$ results in truly severe injuries being overwhelmed in number by injuries to limbs that torso restraining belts of any type would not prevent.

Back seats of the majority of vehicles sold in the United States before the late 1980s had no shoulder belts. When the National Transportation Safety Board documented a set of injuries to lap belted occupants in rear seats that likely would have been reduced by shoulder

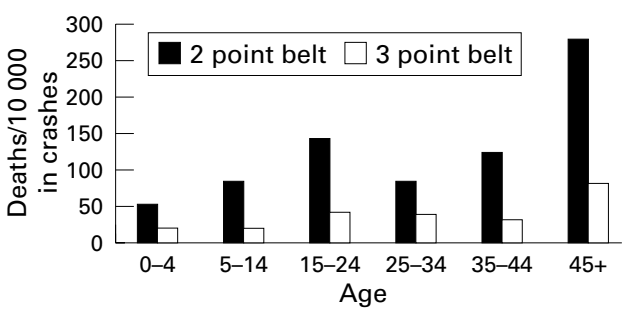

Figure 1 Death rates by occupant age and belt equipment. 
Table 1 Death rate and claimed belt use by age, belt equipment, and vehicle curb weight

\begin{tabular}{|c|c|c|c|c|c|c|c|}
\hline Age & Belts & $\begin{array}{l}\text { Curb } \\
\text { weight* }\end{array}$ & Death rate & Deaths & Crashes & $\begin{array}{l}\text { CDS sample } \\
\text { (No) }\end{array}$ & $\begin{array}{l}\text { Claimed } \\
\text { use (\%) }\end{array}$ \\
\hline \multirow[t]{6}{*}{$0-4$} & \multirow[t]{3}{*}{ Lap } & 1 & 74.3 & 139 & 18706 & 43 & $36+$ \\
\hline & & 2 & 37.5 & 59 & 15746 & 31 & $85 \dagger$ \\
\hline & & 3 & 36.1 & 30 & 8315 & 12 & $99 \dagger$ \\
\hline & \multirow{3}{*}{ Lap/shoulder } & 1 & 35.2 & 245 & 69674 & 245 & $91 \dagger$ \\
\hline & & 2 & 13.7 & 124 & 90293 & 224 & $82 \dagger$ \\
\hline & & 3 & 15.5 & 72 & 46558 & 144 & $94 \dagger$ \\
\hline \multirow[t]{6}{*}{$5-14$} & \multirow{3}{*}{ Lap } & 1 & 89.4 & 177 & 19792 & 56 & 69 \\
\hline & & 2 & 71.8 & 66 & 9193 & 48 & 50 \\
\hline & & 3 & 100.4 & 44 & 4381 & 25 & 51 \\
\hline & \multirow[t]{3}{*}{ Lap/shoulder } & 1 & 33.1 & 300 & 90763 & 248 & 62 \\
\hline & & 2 & 17.6 & 157 & 89232 & 273 & 71 \\
\hline & & 3 & 14.1 & 138 & 98138 & 191 & 80 \\
\hline \multirow[t]{6}{*}{$15-24$} & \multirow[t]{3}{*}{ Lap } & 1 & 125.1 & 325 & 25973 & 87 & 31 \\
\hline & & 2 & 120.2 & 149 & 12395 & 55 & 25 \\
\hline & & 3 & 330.7 & 151 & 4567 & 27 & 18 \\
\hline & \multirow[t]{3}{*}{ Lap/shoulder } & 1 & 52.8 & 666 & 126102 & 378 & 41 \\
\hline & & 2 & 29.8 & 400 & 134356 & 370 & 22 \\
\hline & & 3 & 59.9 & 317 & 52911 & 231 & 44 \\
\hline \multirow[t]{6}{*}{$25-34$} & \multirow[t]{3}{*}{ Lap } & 1 & 86.6 & 87 & 10043 & 19 & 54 \\
\hline & & 2 & 208.3 & 32 & 1536 & 12 & 28 \\
\hline & & 3 & 52.0 & 31 & 5962 & 8 & 2 \\
\hline & \multirow[t]{3}{*}{ Lap/shoulder } & 1 & 53.7 & 169 & 31491 & 91 & 78 \\
\hline & & 2 & 31.9 & 102 & 31958 & 105 & 38 \\
\hline & & 3 & 41.3 & 85 & 20593 & 77 & 55 \\
\hline \multirow[t]{6}{*}{$35-44$} & \multirow[t]{3}{*}{ Lap } & 1 & 187.3 & 43 & 2296 & 8 & 90 \\
\hline & & 2 & 76.9 & 19 & 2470 & 10 & 1 \\
\hline & & 3 & 111.4 & 17 & 1525 & 8 & 68 \\
\hline & \multirow{3}{*}{ Lap/shoulder } & 1 & 95.5 & 82 & 8586 & 33 & 74 \\
\hline & & 2 & 22.5 & 57 & 25382 & 44 & 34 \\
\hline & & 3 & 26.1 & 60 & 23013 & 38 & 46 \\
\hline \multirow[t]{6}{*}{$\geqslant 45$} & \multirow[t]{3}{*}{ Lap } & 1 & 673.9 & 152 & 2255 & 16 & 48 \\
\hline & & 2 & 662.9 & 131 & 1976 & 12 & 4 \\
\hline & & 3 & 148.1 & 179 & 12083 & 21 & 88 \\
\hline & \multirow{3}{*}{ Lap/shoulder } & 1 & 191.3 & 301 & 15733 & 64 & 37 \\
\hline & & 2 & 87.7 & 276 & 31474 & 88 & 53 \\
\hline & & 3 & 56.6 & 390 & 68933 & 142 & 68 \\
\hline
\end{tabular}

$\star 1=<2500,2=2500-2999,3=3000+$ lbs.

† Includes child restraints.

belts, ${ }^{8}$ the study was attacked because of sample size, representativeness, etc. ${ }^{9}$ The issue of the additional protection afforded by shoulder belts was lost for a time in attempts to defend lap belts. The estimated effectiveness of lap belts in rear seats, when used, have ranged from $18 \%{ }^{10}$ to $40 \%,{ }^{11}$ the latter based on data that contain the biases in belt use claims and police miscoding of severity noted above. During 1987-89 vehicles equipped with shoulder belts in rear seats increased substantially. By 1990, all new passenger cars sold in the United States, except convertibles, were required to have shoulder belts at outboard seating positions.

Recently, attendees at two injury conferences have been presented with claims that the addition of shoulder belts did not increase protection to back seat occupants. The methodology of these reports included many of the mistakes

Table 2 Weighted regression of logged death rate/10 000 rear seat occupants in crashes by occupant age, belt configuration, curb weight, and claimed belt use

\begin{tabular}{|c|c|c|c|c|}
\hline & \multicolumn{2}{|l|}{ All cases } & \multicolumn{2}{|c|}{ Claimed belt users } \\
\hline & Coefficient & $95 \% C I$ & Coefficient & $95 \% C I$ \\
\hline Intercept & 4.327 & 4.06 to 4.81 & 3.476 & 3.13 to 3.82 \\
\hline \multicolumn{5}{|l|}{ Occupant age } \\
\hline $5-14$ & 0.097 & -0.09 to 0.18 & 0.028 & -0.20 to 0.25 \\
\hline $15-24$ & 0.800 & 0.59 to 1.01 & 0.748 & 0.49 to 1.01 \\
\hline $25-34$ & 0.793 & 0.47 to 1.11 & 0.538 & 0.17 to 0.91 \\
\hline $35-44$ & 0.575 & 0.16 to 0.99 & 0.540 & 0.02 to 1.06 \\
\hline$\geqslant 45$ & 1.496 & 1.08 to 1.91 & 1.417 & 0.90 to 1.93 \\
\hline \multicolumn{5}{|l|}{ Curb weight } \\
\hline 2500-2999 & -0.693 & -0.50 to -0.88 & -0.168 & -0.41 to 0.07 \\
\hline$\geqslant 3000$ & -0.684 & -0.47 to -0.90 & -0.434 & -0.66 to -0.20 \\
\hline Equipped shoulder & -1.057 & -0.71 to -1.41 & -0.378 & -0.04 to -0.72 \\
\hline Adjusted $R^{2}$ & & 0.86 & & 0.64 \\
\hline
\end{tabular}

of the past. Unverified police reports of severity of injury and belt use were used. ${ }^{7}$ In an analysis of the Fatal Accident Reporting System (FARS), most of the cases that claimed to use shoulder belts in rear seats were in vehicles that did not have them installed. ${ }^{12}$ That claim of no additional effect of shoulder belts was based on miscoded belt types.

Although shoulder belts are unlikely to be discontinued based on such "research", parents who are encouraged to restrain their children in back seats, and adults who occasionally sit there, need information on the reduced risk, if any, of such restraint use. It is important to examine the effect for both children and adults to be sure that if one age group is afforded increased protection, it is not offset by an adverse effect in the other age group.

This paper reports a study of risk of death in crashes among vehicles with and without shoulder belts in back seats, controlling for occupant ages, vehicle size, vehicle age, and claimed belt use. Although the issue of misreported use is not resolved, the net effect of the equipment, that is, the effect of the combination of use and effectiveness when used, is clarified.

\section{Methods}

Data from two United States databases, the Crashworthiness Data System (CDS) and the FARS, were combined to produce rates of death per crash exposure for combinations of equipment, occupant age, vehicle weight, and vehicle age. CDS is a nationally representative sample of towaway crashes in the United States, concentrating on vehicles up to five years old. ${ }^{13}$ Exposure to crashes to rear seat occupants, by claimed belt use, in 1987-97 passenger cars among categories of the mentioned factors during the first five years of vehicle use was tabulated from the 1988-96 CDS files. The national estimate was obtained by summing the sampling ratio for each case (1997 models that went on sale in Fall, 1996 are included).

FARS is a census of virtually all of the fatalities that occur on public roads in the United States. ${ }^{14}$ Fatalities to occupants of back seats were summed in the same calendar years among the same categories of equipment, age, vehicle size, vehicle age, and claimed belt use as those obtained from CDS.

Rates of death per 10000 rear occupants of rear outboard seats, excluding convertibles, in crashes were then calculated and analyzed by weighted regression. Since the CDS is a sample and there is substantial variation in sample size among the categories of predictor variables, the rates were weighted in each combination of categories of predictor variables by dividing sample size in the category combination by $p(1-p)$ where $p=$ the fatal rate per estimated number in crashes.

To reduce coding error as to equipment available, lists of vehicles by make and model year during 1987-89 were examined to determine when shoulder belts were installed in back seats. ${ }^{15-17}$ The vehicles in CDS and FARS 


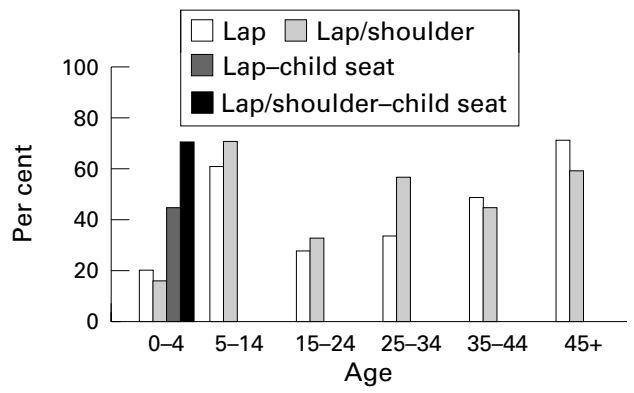

Figure 2 Claimed restraint use by occupant age.

were compared with the lists and the vehicle was classified as having lap only or lap/shoulder belts. During the period studied, make and model of vehicle and seating position of occupants were unknown for fewer than $1 \%$ of cases. Age of occupant was unknown for about $2 \%$ of occupants and belt use was coded as "unknown" in about 7\% of cases. As noted, the latter is not accurate.

\section{Results}

The death rates by occupant age and belt equipment are shown in fig 1 . In each age category, the death rates in vehicles equipped with shoulder belts are substantially less than in those with lap belts only. The data, including categorization by vehicle size, is presented in table 1 . A weighted regression of the logarithm of the rates, separately for all crashes and crashes in which belt use was claimed, is presented in table 2. Because the effect of occupant age and vehicle size is non-linear, the $\log$ of the rates was analyzed. Each of these factors contribute to differences among rates, but the data fit the model much better when all cases are considered rather than when claimed belt use is considered. Controlling for the other factors, death rates are lower in vehicles with shoulder belts, are lower among children and highest for those 45 and older, and are lower among occupants of midsized and larger cars.

Figure 2 presents claimed restraint use by occupant age. Child restraints are claimed to be used more in crashes of cars with lap/ shoulder belts $(71 \%)$ than those with lap belts $(46 \%)$. Restraint use is claimed more often in lap/shoulder equipped cars by occupants up to age 34 and the use of lap belts is claimed more often by occupants 35 and older. However, only $16 \%$ of the occupants were 35 and older. About $46 \%$ of the occupants were less than 15 years old.

Because older vehicles may have less belt use and be less crashworthy due to improvements in designs of later models, the effect of vehicle age was examined in combination with age of occupants and belt equipment. No significant effect of vehicle age was found.

\section{Discussion}

The apparent reduction of death in rear seats associated with installation of shoulder belts could be partly the result of increased belt use in vehicles equipped with shoulder belts. Claimed use and effect, however, are not consistent among occupants 35 years and older. Although older occupants claim to use shoulder belts less than lap belts, their deaths are lower in shoulder belt equipped cars. The reduced deaths and claimed belt use are more consistent for children and young adults, but claimed use may not be precisely accurate in those age groups as well. Nevertheless, since the death rate is reduced by the combination of effectiveness and use in all age groups, the reduced deaths associated with installation of shoulder belts clearly indicates their superiority to lap belts.

Shoulder belts reduce severity of injury because they distribute loads in crashes over more belt surface. Therefore, the load is less concentrated at any point on the belts. Claimed use is likely invalid in sufficient instances such that attempts to evaluate the effectiveness of belts based on claimed use in the era of belt use laws will produce invalid estimates. Because death rates in cars equipped with shoulder belts in rear seats are substantially lower than in cars equipped with lap belts at prevalent use rates, shoulder belt users can be assured of less risk.

1 Robertson LS. Estimates of motor vehicle seat belt effectiveness and use: implications for occupant crash protection. Am f Public Health 1976;66:859-64.

2 National Highway Traffic Safety Administration. Report to Congress on the benefits of safety belts and motorcycle helmets based on data from CODES, the Crash Outcome Data Evaluation System. Washington: US Department of Transportation, 1995.

3 Evans L. The effectiveness of seat belts in preventing fatalities. Accid Anal Prev 1986;18:229-41.

4 Robertson LS. Mistaken assertions on reducing motor vehicle injury. Am f Public Health 1997;87:295-6.

5 Robertson LS. Shoulder belt use and effectiveness in cars with and without window shade slack devices. Hum Factors 1990;32:235-42.

6 Robertson LS. Injury epidemiology: research and control strategies. New York: Oxford University Press, 1998.

7 Padmanaban J, Ray RM. Safety performance of rear seat occupant restraint systems. Seattle: 36th Annual STAPP Car Crash Conference, 1992.

8 National Transportation Safety Board. Performance of lap belts in 26 frontal crashes. Washington: National Transportation Safety Board, 1986.

9 Campbell BJ. The effectiveness of rear-seat lap belts in crash injury reduction. Detroit: Society of Automotive Engineers Paper No 870480, 1987.

10 Evans L. Rear seat restraint system effectiveness in preventing fatalities. Accid Anal Prev 1988;20:129-36.

11 Kahane CJ. Fatality and injury reducing effectiveness of lap belts for back seat occupants. Detroit: Society of Automotive Engineers Paper No 870486, 1987.

12 Warner CY, Meissner U, Padmanaban J. Usage and effectiveness of rear-seat-belt restraints in severe frontal crashes. Presented at the ISATA, Florence, Italy, 1997.

13 National Center for Statistics and Analysis. National accident sampling system (NASS), crashworthiness data subsystem, analytical users manual. Washington: National Highway Traffic Safety Administration, 1989.

14 National Highway Traffic Safety Administration. Fatal accident reporting system 1988. Washington: National Highway Traffic Safety Administration, 1989

15 Insurance Institute for Highway Safety. 1987 cars with standard rear seat shoulder belts. Status Report 1986; 21(14):2.

16 Insurance Institute for Highway Safety. 1988 cars with standard rear seat shoulder belts. Status Report 1988;23(2):

17 National Highway Traffic Safety Administration. Passenger cars with rear lap/shoulder belts. Consumer information. Washington: US Department of Transportation, 1989. 